EJMBE

26,2

252

Received 19 October 2016 Accepted 1 May 2017

\section{The contribution of tangible and intangible resources, and capabilities to a firm's profitability and market performance}

\author{
Rifat Kamasak \\ Department of Business Administration, Bahcesehir University, Istanbul, Turkey
}

\begin{abstract}
Purpose - The purpose of this paper is to investigate the relative contribution of tangible resource (TR) and intangible resource (IR), and capabilities on firm performance based on the measures of market share, sales turnover and profitability.

Design/methodology/approach - A cross-sectional survey research design was used in the study. The modified version of Galbreath and Galvin's (2008) resource-performance questionnaire which included a total number of 45 questions was applied on 243 Turkish firms operating in different industries. The data collected were analysed by hierarchical regression analysis.

Findings - The findings revealed that IRs and capabilities contributed more greatly to firm performance compared to TRs. However, in contrast to the proposition of resource-based theory that views capabilities as the most important skills that underpin the development and deployment of both TR and IR, capabilities offered rather limited additional explanatory power to the prediction of firm performance only with respect to profitability against the combined effects of TR and IR.

Originality/value - The vast majority of the empirical resource-based view (RBV) research concentrates on developed countries and very little is known about results outside of this domain. This study employs Turkish business databases to assess the relative importance of TR and IR and capabilities on performance differences among firms in Turkey which was the 17th largest economy in the world trade in 2016. Second, in the RBV literature, limited research tests the contribution of capabilities to firm success after simultaneously accounting for the effects of other resources (namely, TR and IR) available to the firm. Finally, this research offers practical contributions to executives and managers who have to make adequate decisions for firm survival and growth in the competitive business arena.
\end{abstract}

Keywords Firm performance, Emerging markets, Capabilities, Resource-based view,

Tangible and intangible resources

Paper type Research paper

\section{Introduction}

Strategy researchers (Ambrosini and Bowman, 2009; Kor and Mesko, 2013; Molloy and Barney, 2015) have suggested that intangible resources (IRs) were considered as the most likely sources of firm success because they are not easily acquired and replicated in factor markets. However, since firms are bundles of IR and tangible resource (TR), it is very unlikely for a firm to compete on the basis of a single IR, important as it may be (Sirmon et al., 2011; Kor and Mesko, 2013). Moreover, since TR and IR are static in nature (Teece, 2007; Helfat and Peteraf, 2015),

(C) Rifat Kamasak. Published in the European Journal of Management and Business Economics. Published by Emerald Publishing Limited. This article is published under the Creative Commons Attribution (CC BY 4.0) licence. Anyone may reproduce, distribute, translate and create derivative works of this article (for both commercial and non-commercial purposes), subject to full attribution to the original publication and authors. The full terms of this licence may be seen at http://creative commons.org/licences/by/4.0/legalcode

The author declares that the paper was produced from the author's own previous thesis. The author would like to thank Professor Simon James for his valuable contribution to the paper.
European Journal of Management and Business Economics Vol. 26 No. 2, 2017 pp. $252-275$

Emerald Publishing Limited 2444-8451 DOI 10.1108/EJMBE-07-2017-015 
organisations must use some other mechanisms that can integrate and reconfigure resources, and renew or alter their resource mix to be able to cope with environmental changes. Several researchers (Weigelt, 2013; Wang et al., 2015) suggest that only the capabilities can turn these static resources into dynamic nature and transform them to create a new configuration of resources that can sustain competitive advantage. Therefore, over the last quarter century, a large body of strategic management research which includes theoretical and empirical studies has worked on the understanding of how firms' different sets of resources and capabilities lead to performance variations among firms (Molloy and Barney, 2015; Morris et al., 2017).

Nevertheless, against the main prescription of resource-based view (henceforth known as the RBV) which points IRs as the most likely sources of competitive advantage and theorises that TRs offer no or very limited contribution to overall firm performance, little empirical evidence within the RBV stream exists to falsify the claim (Galbreath and Galvin, 2008; Renzi and Simone, 2011; Schriber, 2015). To be able to test the truthiness of this claim, TR and IR should be used together in the same analysis. Moreover, resources are not productive on their own and it is the capabilities that assemble, integrate and manage the bundles of resources (Teece, 2007; Maritan and Peteraf, 2011).

Huselid (1995) states that "one-dimensional studies are likely to underestimate the biases associated with examining an individual resource as such studies do not simultaneously account for the effects of other factors" (p. 642). Similarly, Galbreath and Galvin (2006, p. 151) highlight that "studying an individual IR (e.g. reputation, brand) apart from other factors might offer misleading results". Hence, any research that aims to test the effects of resources on firm performance should include capabilities as well as TR and IR in the analysis. However, only a few RBV studies (e.g. Fahy, 2002; Galbreath and Galvin, 2008; Schriber, 2015) have examined the relative effects of TR and IR on firm success in the same study and the justification of these studies is compelling particularly for validation of the main prescription of the RBV (Makhija, 2003; Galbreath and Galvin, 2008; Schriber, 2015).

Although the main prescription of the RBV points to firm-level factors as the most important determinants of firm performance, it does not omit the industry effects completely (McGahan and Porter, 1997; Short et al., 2009). According to Porter (1980), having analysed an industry in terms of its structural attractiveness, firms must choose a strategy in order to create a unique, defendable position in their industry. Then, the firm should acquire or otherwise obtain the necessary resources (tangible and intangible) to implement its stated strategy. This interaction between resources and industry structure variables should be considered in RBV studies to account simultaneously for the effects of every factor in explaining performance differences (Huselid, 1995; Morgan et al., 2009).

In the context of the main prescription of the RBV and its theoretical framework, the question of relative effects of TR and IR along with the capabilities on firm success has always remained an important issue to be answered. Thus, the ultimate research question of this study is: what are the relative effects of TR and IR, and capabilities in explaining firm performance?

This study aims to make potential contributions to RBV in three main areas: first, the vast majority of the empirical RBV research concentrates on developed countries and very little is known about results outside of this domain (Cavusgil et al., 2013). Kamal (2011, p. 21) states that "specific research into emerging markets is necessary since the unique characteristics of emerging economies may prove many of the findings in developed economy settings invalid in an emerging economy setting". In this context, this study employs Turkish business databases to assess the relative importance of TR and IR and capabilities on performance differences among firms in Turkey which was the 17th largest economy in the world trade in 2016 (IMF World Economic Outlook, 2017).

Second, in the RBV literature, limited research tests the contribution of capabilities to firm success after simultaneously accounting for the effects of other resources (namely, TR and IR)
Contribution of TR and IR 
EJMBE

26,2

254 available to the firm (Galbreath and Galvin, 2006, 2008; Molina-Azorin, 2012). The exclusion of other potentially important resources and the use of only a single resource (or a capability) or a few resources to measure the resource - firm performance relationship, may lead to overestimating results and undermine the complexities of competitive advantage (Galbreath, 2004). Moreover, the RBV does not repudiate the influence of industry structure factors on firm performance completely (Porter, 1991; Peteraf and Barney, 2003). Hence, testing the significance of the IRs and capabilities against the effects of other resources and even industry structure factors with a different empirical approach cannot only offer a more stringent test of intangibles' contribution to firm performance than previous studies but it may also contribute to the verification of the RBV's main prescription.

Finally, management research should offer practical contributions to executives and managers who have to make adequate decisions for firm survival and growth in the competitive business arena. It should be noted that decisions about where investments should be placed have important implications for management practice. For example, if capabilities (e.g. human capital, networking capabilities and business processes) are the most important determinants of performance, then the firms need to focus and invest on their dynamic skills, if the situation is in favour of IRs (e.g. brand, corporate image and organisational culture), then attention should be paid to unique resource stocks. As such, this study seeks to help managers with respect to resource investment decisions by revealing the key determinants of firm success and their relative importance on performance.

This research thus focusses on testing the contribution of different resources on firm performance. In the first section, previous literature in relation to resource-based theory which investigates firm-level resource and capability effects on performance was examined and accordingly, a number of hypotheses were developed to be tested. Afterwards, the methods that were employed in the study for empirical testing purposes were explained and the results were presented. In the final section, within the context of Turkish business environment and sample data, the findings were discussed, managerial implications were provided and the limitations of research along with future research directions were highlighted.

\section{Literature review}

In the last 30 years, RBV have paid considerable attention to internal firm-level factors to explore unexplained variance in firm performance. Wernerfelt (1984) emphasised the internal workings of a firm but did not entirely dismiss industry structure effects, and further linked firm performance to the idiosyncratic and heterogeneous resources of the organisations and proposed that acquisition of these resources are critical for earning above normal returns. Wernerfelt (1984) described the firm as bundles of resources and argued that "resources and products are two sides of the same coin" (p. 171). Afterwards, Barney (1991) suggested that competitive advantage can only be generated and sustained by firmlevel resources that are valuable $(V)$, rare $(R)$, inimitable $(I)$ and non-substitutable $(N)$ - the so-called VRIN criteria framework and claimed that only resources that are intangible in nature possess these criteria. Therefore, in considering the heterogeneity among firms in resources as fundamental in explaining why some firms outperform others, the RBV posits such a position (Barney, 1991).

\subsection{IRs as the focal point of the RBV}

The RBV scholars (Barney, 1991; Kor and Mesko, 2013) claim that IRs cannot be readily obtained in the factor markets and copied by competitors easily. Along with several researchers (Dierickx and Cool, 1989; Peteraf and Barney, 2003), Barney (1991) proposed that the sources of inimitability can be explained by three isolating mechanisms: historical uniqueness, causal ambiguity and social complexity. In addition to these mechanisms, time 
compression diseconomies and interconnectedness have been widely discussed in strategic management literature (Dierickx and Cool, 1989; Bharadwaj, 2000).

Historical uniqueness refers to "unique historical events such as a firm's founding, being taken over by a firm sometime in the past by legendary managers or owners, emergence of the unique, valuable organisational culture in the early stages of a firm's history, choice of facility location decisions which created distinctive location advantages in the following years and choice of market entrance decisions as a first mover, that determined the long-term performance of the firm" (Barney, 1991, p. 108). These unique historical conditions endowed firms with resources that cannot be controlled by rivals and that cannot be imitated.

Causal ambiguity refers to "the ambiguity surrounding the connection between a firm's resource portfolio and its performance" (Bharadwaj, 2000, p. 171). Barney (1991) suggests that causal ambiguity exists when the link between its resources and sustained competitive advantage is not understood by competing firms. In this situation, it is very difficult for imitating firms to duplicate a successful firm's strategies since they do not understand exactly what makes a firm successful. Social complexity can be found where resources are based on complex social phenomena (Barney, 1991, Eesley et al., 2014) and it significantly constraints the ability of other firms to imitate these resources. Socially complex resources such as interpersonal relations among managers, corporate reputation of a firm among customers and suppliers and organisational culture are imperfectly imitable because, although it may be possible for competitors to specify and replicate (or engineer) these resources, there is no guarantee that they can achieve similar valuable benefits since socially complex resources are not subject to direct and standard management (Barney, 1991). In a similar line, the elements of intellectual property assets such as copyrights, patents, registered designs and trademarks that provide legal protection to firms preserve the economic benefits of the firms from being eroded and cannot be duplicated by competitors (Chari and David, 2012; Grimpe and Hussinger, 2014). Unique organisational culture can be a great source of competitive advantage since it has strong roots with being different, more creative and innovative (Gupta et al., 2017). Through possession of complex and inimitable organisational culture which always supported its employees use their skills freely, Sony, Virgin and Apple became among the most innovative firms in global markets. Moreover, as an example of presenting how value creation ability has shifted from TR to IR, Apple has changed its business from selling hardware to selling design and emotions with its aesthetically pleasing products such as the candy-coloured iMac, the diminutive iPod Nano and the legendary iPhone and iPad.

Another mechanism time compression diseconomies which is related to "the observed tendency of the costs of resource accumulation to rise within a given time interval" (Lockett et al., 2009, p. 15) has also been widely mentioned in the literature. According to Dierickx and Cool (1989, p. 1507), time compression diseconomies refers to "the time needed to develop resources through learning, experience, firm-specific knowledge or, trained proficiency in a skill". Dierickx and Cool (1989) argue that the inimitability of a resource is linked to the characteristics of the resource accumulation process. For example, organisational culture is such a unique IR that can be difficult for competitors to replicate since it possesses the conditions of asset specificity and time compression diseconomies (Dierickx and Cool, 1989; Lockett et al., 2009). Corporate reputation as an IR involving an external overall evaluation of firms' actions and past performance in creating stakeholder value (Dowling, 2016) can be accrued in the minds of stakeholders over time. Research (i.e. Wei et al., 2017; Raithel and Schwaiger, 2015) found that because of its unique and complex nature, favourable corporate reputation was linked to firm performance and helped firms sustain competitive advantage in the markets. Similarly, sophisticated in-secret technology for the manufacturing firms (or service know-how for the services firms)

Contribution of TR and IR 
EJMBE 26,2 may also become a socially complex and causally ambiguous resource over time. A similar and good example to the creation of competitive advantage through this kind of an in-secret technology ownership is "the cross-docking system of retail giant Wal-Mart" (Galbreath, 2004, p. 121). In the early years of Wal-Mart, whilst supply chain software of the firm contained commodity-type of information technologies that can be obtained easily in the factor markets, the system underwent such a complex customisation over years that none of the competitors could afford to imitate it. In a more recent study, Arend et al. (2014) who point knowledge as the most strategically important firm resource found that socially complex embedded internal knowledge were significantly correlated on firms' survival, return on asset (ROA), and Tobin's $q$ of firms.

Interconnectedness which was discussed by Dierickx and Cool (1989) refers to "the value of a resource being inexplicably linked to the presence of another complementary or co-specialised resource" (Bharadwaj, 2000, p. 171). Lockett et al. (2009) explain resource interconnectedness as the link between the existing stock of resources and the cost of adding an increment of another resource to the firm's stock. The closer and more complicated the link, the more difficult for rivals to understand the process and to imitate the competitive resource. A manufacturer which lowers its new product development costs via feedback benefits derived from the same firm's customer service department can be a good example for value creating and imitation preventing resource interconnectedness (Dierickx and Cool, 1989).

Consequently, given their unique nature that stems from social complexity, causal ambiguity, path-dependency, historical uniqueness, and asset specificity, IRs that offer economic benefits to firms which cannot be easily acquired and replicated should have a higher impact on firm success than tangible assets. Therefore, this study offers the following hypothesis:

H1. IRs will make a larger contribution to firm performance than that of TRs.

\subsection{Capabilities as the dynamic enabling mechanisms}

The dynamic capabilities (DCs) perspective posits that the organisations must integrate and reconfigure their resources and capabilities to renew or alter their resource mix to be able to cope with environmental changes (Teece, 2007; Helfat and Peteraf, 2015). Several empirical studies identified specific examples of DC such as customer relationship (Chari and David, 2012), supply chain management (SCM) (Barney, 2012), client-specific capabilities (Weigelt, 2013), managerial ability (Helfat and Peteraf, 2015) and geographical and network ties (Ozer and Zhang, 2015). Although different researchers identified different types of capabilities, the most common point that can be inferred from these identifications is that DCs are managerial and organisational processes and their basic role is "to assess the firm's extant resource base and transform it to create a new configuration of resources that can sustain competitive advantage" (Ambrosini and Bowman, 2009, p. 32).

Compared to TR and IR, capabilities certainly remained the most amorphous and complicated to define among the constructs that constitute the RBV (Galbreath, 2004; Di Stefano et al., 2014). However, despite this complexity, the RBV scholars have had a common point that human capital (Coff and Kryscynski, 2011; Ployhart and Moliterno, 2011; Kor and Mesko, 2013; Chatterji and Patro, 2014), networking capabilities (Acquaah, 2012; Weigelt, 2013; Ozer and Zhang, 2015) and business processes (Ray et al., 2004, 2013; Hult et al., 2007; Barney, 2012; Weigelt, 2013) were the most influential as well as vital capabilities on the way of creating performance through building, coordinating, integrating and reconfiguring organisational resource bases and competencies of firms (Teece, 2007).

2.2.1 Human capital. Ployhart and Moliterno (2011) define human capital as a "unit-level capability that is created from the emergence of individuals' knowledge, skills, abilities, and 
other characteristics" (p. 127). Human capital that comprises the skills, expertise, creativity, innovative thinking, pro-activity, collective learning, and know-how of employees and managers was considered among the most important determinants of firm success by the RBV scholars (Coff and Kryscynski, 2011; Chatterji and Patro, 2014). Teece (2007) suggests that a change in the configuration of resource base can only be achieved through market-oriented and timely strategic managerial decisions that continuously scan the capabilities landscape and environmental changes. Hall (1992) considers skills and know-how of employees as the main driver of a firm's performance since all decisions regarding how, where and when a firm will deploy its resources are made by employees. Chatterji and Patro (2014) explained the role of strategic decisions of managers and talented employees with creative and innovative skills on the way of creating firm performance through Google and Facebook cases in the context of DC framework. In a recent study, Sánchez et al. (2015) found that strategic human resource practices influence employee behaviour and generate positive effects in firm performance. Therefore, human capital as a $\mathrm{DC}$ is held to be among the most important sources of firm performance.

2.2.2 Networking capabilities. Networking capabilities that refer to the ability to build and maintain relationships external to the firm was linked to the generation of firm performance (Acquaah, 2012; Weigelt, 2013; Ozer and Zhang, 2015). Ozer and Zhang's (2015) research which examined the effects of multiplex network ties such as buyer-supplier equity, network structure and industry clusters as capabilities on innovation performance found a rigorous relationship. Similarly, Acquaah's (2012) study found that the firms which can use social networking relations and firm-specific managerial experience effectively yielded much better performance compared to other firms.

Networking capabilities provide immense benefits to the firms such as transfer of specialised knowledge (know-how), promoting customer and brand loyalty, reaching to scarce resources and closed markets, and boosting the learning ability of the firm (Weigelt, 2013; Ozer and Zhang, 2015). Moreover, especially in emerging markets where government, bureaucracy and local authorities are too much involved in business, it is very difficult for firms to reach scarce raw materials offered by local suppliers or state-owned enterprises, to gain access to distribution and communication channels controlled by local authorities, and to obtain licences issued by home governments without establishing good relations with politicians (Cavusgil et al., 2013). In fact, networking relations may not be limited to government and bureaucracy. Emerging markets are called network societies where trust-based relations and longstanding connections are highly valued and social and business environment is highly affected from these relationships as a consequence of the dominant collectivist culture in these countries (Cavusgil et al., 2013).

Therefore, well-established relations with suppliers, distributors and customers can provide superior advantages to firms. For example, the long-term and trust-based relationships between Ülker, the Turkish confectionery manufacturer and the owner of Godiva and United Biscuits UK, and local distributors and suppliers led to competitive advantage by enabling the firm to penetrate the African, East European and Middle Eastern markets better than its multi-national rivals such as Nestlé, Kraft's Cadbury and Milka from developed countries. As suggested by Dierickx and Cool (1989), relationships represent a capability which is built through historical and path-dependent trajectories, different to be observed by rivals, and cannot simply be traded on open. Hence, these idiosyncrasies create a formidable barrier for replication and make networking capabilities essential to a firm's success.

2.2.3 Business processes. Business processes are described as "the actions that firms engage in to accomplish some business purpose or objective" (Ray et al., 2004, p. 24). Business processes provide essential infrastructural support for functional integration and maintain effective information flows that are associated directly with overall firm performance.
Contribution of TR and IR

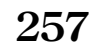


EJMBE

26,2

For example, sophisticated in-house developed or purchased software such as intranet or electronic data interchange (EDI) enabled many banks to make fast and effective decisions and increased their customer services quality substantially by combining customer intelligence, credit, risk and funding management functions. Moreover, business processes can help firms to reveal, share and transfer tacit and embedded knowledge in the organisation through IT-based knowledge management initiatives. Many firms (e.g. Lilly and Estée Lauder) established "I have an idea" type digital platforms, which brought all internal and external parties from all over the world together via an on-line informal network to share their ideas with respect to new product and services along with the suggestions for the operational effectiveness of the firm. As a consequence, many helpful and innovative ideas emerged from those applications.

As another business process, an effective supply chain system enables a firm to transmit its raw materials, finished goods and services in a seamless way (Hult et al., 2007; Barney, 2012). As a consequence, the firms find substantial improvements in production costs and order fulfilment cycling times (the length of time between taking an order and delivery of the needed product to the customer) that are directly linked to firm performance (Ray et al., 2004; Hult et al., 2007). Estée Lauder's Global Supply Chain system LEAN can be a good example to illustrate how an ERP can provide operational excellence and continuous improvement in different processes of a firm. A similar application which combines all work processes and a system for managing the creation, review, approval, distribution and storage of technical specifications needed to run a consumer packaged goods company is used by $\mathrm{P} \& \mathrm{G}$ under the agreement MatrixOne.

Barney (2012, p. 4) states that "home grown purchasing and supply chain management capabilities are likely to be sources of advantage". In the early years of Wal-Mart, whilst supply chain system of the firm contained commodity-type of information technologies that can be obtained easily in the factor markets, the system underwent such a complex customisation over years that none of the competitors could afford to imitate it. Given their aforementioned roles and features, business processes are also likely to be among the most critically important sources of firm performance. Thus, based on the previous literature that was examined so far, the following hypotheses are offered.

In respect to the $H 2$, TRs are described as observable, easy to acquire, and easy to replicate and do not possess the VRIN criteria to be termed as strategic resources. However, capabilities are argued to be tacit in nature, causally ambiguous and very difficult to duplicate (Barney, 1991; Galbreath, 2004). Besides, prior RBV research (Galbreath and Galvin, 2008; Schriber, 2015) suggests that the impact of capabilities on performance is greater than TRs, therefore:

H2. Capabilities will make a larger contribution to firm performance than that of TRs.

Capabilities are consider as a "superior" resource because of "their capacity to deploy resources, usually in combination, using organisational processes, to effect a desired end" (Fainshmidt et al., 2016, p. 1348). Namely, they characterise the dynamic, non-finite mechanisms enabling the firm to acquire, develop and deploy all resources (including intangible ones) to create organisational performance and sustain competitive advantage (Dierickx and Cool, 1989; Helfat and Peteraf, 2015). Besides, IRs have been described as resources that are created as a result or outcome of capabilities (Galbreath and Galvin, 2008; Helfat and Martin, 2015; Fainshmidt et al., 2016). For example, unique brands and a favourable corporate reputation are the results of the prior actions of the firm's managerial capabilities that comprise "managerial intentionality, deliberation, decision making, and action skills" (Helfat and Martin, 2015, p. 1285). Similarly, new products, trademarks, patents and copyrights are the results of the knowledge management and processing capabilities of the firms' (Monteiro and Birkinshaw, 2016; Yayavaram and Chen, 2015). The DC view argues that "capabilities comprise more 
metaphysical strategic insights, possess the highest levels of causal ambiguity and complex capacities that are more difficult to observe and decode" (Fainshmidt et al. 2016, p. 1354). These features make capabilities more resistant to competitor duplication than IRs. Therefore it is hypothesised that:

H3. Capabilities will make a larger contribution to firm performance than that of IRs.

Hypotheses that have been posited so far, mainly explored distinct associations between capabilities and TR and IR (Galbreath, 2004). But, capabilities are predominantly viewed as the most important skills that underpin the development and deployment of both TR and IR in resource-based theory (Ambrosini and Bowman, 2009; Molloy and Barney, 2015). Based on this view, it is hypothesised that:

H4. Capabilities will make a larger contribution to firm performance than the combined contributions of TR and IR.

\section{Methods}

\subsection{Sample and informant selection}

The sample was selected from the database of Istanbul Chamber of Industry (ISO) that announced the largest 1,000 firms of Turkey (ISO-1000) from different sectors annually (ISO-1000 Database, 2016). The sample designed for multiple research purposes was the best available and relevant sample that could be found in the country. Therefore, the largest 1,000 firms of 2015 were chosen and the valid names and e-mails of senior-level executives of the companies were obtained for this study. The $\mathrm{CEO}$ or an equivalent top manager who deal with strategy issues and have adequate knowledge to assess the firm's resource base and authority to answer the questions is chosen as the key informant (Hall, 1992; Galbreath and Galvin, 2006, 2008). Because the unit of analysis in this study was at the firm level, a single informant was used and the questionnaire was mailed to only one executive from each firm.

\subsection{Administration of survey}

A cross-sectional survey research design was used in the study. The measurement instrument was pre-tested by administrating a pilot study in order to assess the wording and construct reliability and validity (Saunders et al., 2007). The pilot study was conducted on a sample of $42 \mathrm{MBA}$ students in a foundation university in Istanbul. The participants were middle- and lower-level managers who had sufficient knowledge about the objectives of the research. The questionnaire included some space at the end of the last section for the feedback of the respondents about how the measurement instrument could be improved. No difficulty to understand the questionnaire was observed. After the pilot study, the questionnaires were sent to the e-mail addresses of the top level executives as a web-link with a covering letter that assures the privacy and confidentiality of respondents. Three weeks after the initial mailing, a reminder follow-up e-mail was also sent to be able to increase the response rate of the study (Saunders et al., 2007). A total of 243 useable questionnaires were obtained, yielding a response rate of 24.3 per cent. The details about the composition of the sample are provided below.

3.2.1 Firm size and age. Whilst the number of full-time employees ranged from 53 to 29.372, the number of years in business ranged from 4 to 93. The details regarding means and standard deviations were shown in Table I.

3.2.2 Primary business activity. Primary business activities of the participant firms were automotive, computer and software, textile and apparels, retail, tourism, banking and finance, drugs, oil and petrochemicals, construction, logistics and transportation, telecommunications, and food. The percentage of firms in each sector was depicted in Table II.
Contribution of TR and IR 
EJMBE

26,2

260

3.2.3 Non-response bias. Non-response bias which occurs when respondents differ from non-respondents in the sample can be considered as a common problem in surveys (Saunders et al., 2007). In order to test representation capability of the respondents for the broader population, the means of early (131 responses -54 per cent of the sample) and late respondents (112 responses - 46 per cet of the sample) on two-key demographic variables were compared statistically via independent samples $t$-test (Saunders et al., 2007). As it was presented in Table II, the comparison of early and late respondents did not reveal a significant difference on firm size $(t=-2.386, p=0.354)$ and age $(t=2.792, p=0.193)$. Hence, non-response bias was not considered as a serious issue in the study and the respondents appeared to be representative of the broader population (Table III).

\subsection{Measurement instrument}

The modified version of Galbreath and Galvin's (2008) resource-performance questionnaire which was mainly developed based on the studies of Carmeli and Tishler (2004), Fahy (2002), Spanos and Lioukas (2001) and Hall (1992) was employed in this study. The questionnaire included a total number of 45 questions: 27 questions to measure the effects of resources including both tangibles and intangibles, and capabilities, 12 questions to control the effects of industry structure factors, three questions to measure market and financial performance, and two questions for the demographics (age and size). And the last question aimed to categorise the primary business activity of the firms. The items of the questionnaire were mentioned below and presented in Table IV.

Table I.

Firm size and age

\begin{tabular}{lrrrrl}
\hline & $n$ & Mean & SD & Min. & Max. \\
\hline Firm size & 243 & 431.63 & 543.26 & 53 & 29.372 \\
Firm age & 243 & 34.57 & 31.25 & 4 & 93 \\
\hline
\end{tabular}

Table II.

Business activities of the firms

Business activity

Automotive

Banking and finance

Computer and software

Construction

Drugs

Food

Logistics and transportation

Oil and petrochemicals

Retail

Telecommunications

Textile and apparels

Tourism

Other

Total

\section{Frequency}

$\begin{array}{rr}24 & 9.9 \\ 21 & 8.6 \\ 8 & 3.2 \\ 19 & 7.8 \\ 10 & 4.1 \\ 18 & 7.4 \\ 11 & 4.5 \\ 15 & 6.2 \\ 27 & 11.2 \\ 4 & 1.7 \\ 35 & 14.5 \\ 13 & 5.3 \\ 38 & 15.6 \\ 243 & 100.0\end{array}$

Table III.

Non-response bias

\begin{tabular}{lrccc}
\hline & $t$ & df & Sig. (2-tailed) & Mean difference \\
\hline Firm size & -2.386 & 237 & 0.354 & -12.78 \\
Firm age & 2.792 & 241 & 0.193 & 3.48 \\
\hline
\end{tabular}




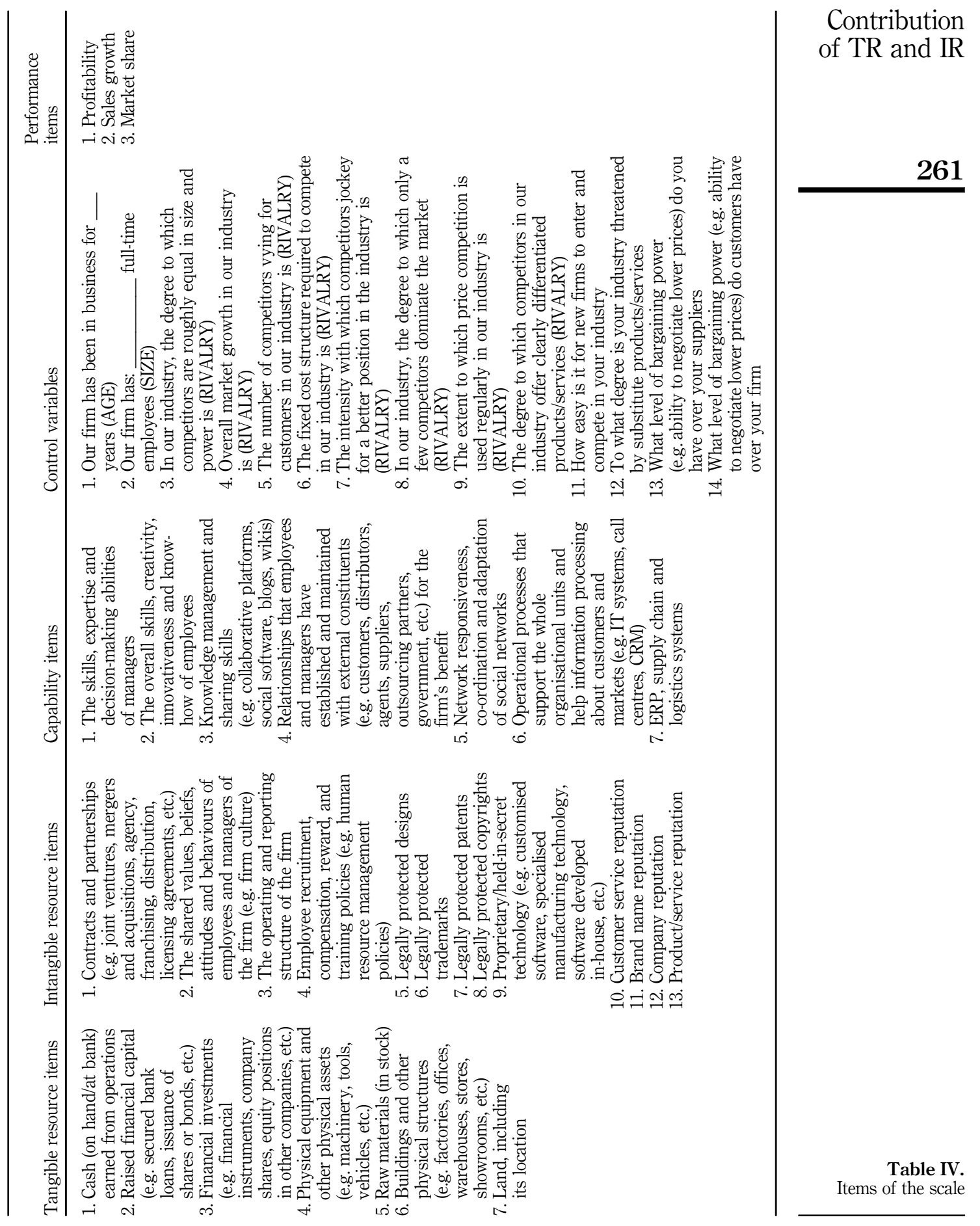


EJMBE 26,2
3.3.1 TRs. TRs were measured by the items such as cash earned from operations, financial investments (e.g. stocks, bonds, equity positions in other companies), land, raw materials (in stock), physical structures and raised capital.

3.3.2 IRs. IR items include company reputation, organisational culture, customer service reputation, legally protected copyrights, designs and patents, human resource management policies, organisation structure, product/service reputation, and trademarks.

3.3.3 Capabilities. Capability items that include human capital (skills of both managers and employees), networking abilities (relationships that were established and maintained with external constituents) and business processes such as IT systems, ERP, supply chain, and logistics systems, knowledge sharing through collaborative platforms, and social software.

3.3.4 Performance items. Firm performance items were adapted from the scale of Spanos and Lioukas (2001) that includes market share, sales growth and profitability items. Hence, this study treats firm performance as a multi-dimensional rather than a single construct. Respondents were asked to indicate their firms' performance compared to competitors for the previous three-year period (2010-2012) in order to "proximate a notion of sustained performance and to mitigate against temporal fluctuations" (Galbreath and Galvin, 2008, p. 113). This study employs perceived measures to assess performance which means that subjective measures were used instead of objective measures. Perception-based performance measurement is common in strategy research (i.e. Galbreath and Galvin, 2008; Fonti et al, 2017; Quigley et al, 2017). Several researchers (i.e. Venkatraman and Ramanujam, 1986; Spanos and Lioukas, 2001; Bauer and Matzler, 2014) suggest that even if information is obtained by subjective measures in a sample survey research, the results are often very accurate since the measurement instrument is specifically designed to address the research questions.

However, the common use of subjective measures does not support the idea that subjective measures are more reliable than objective measures (Dess and Robinson, 1984; Venkatraman and Ramanujam, 1987; Bauer and Matzler, 2014). Besides, subjective measures should not be deemed as convenient substitutes for objective measures of a firm's financial performance. Dess and Robinson (1984) found a strong correlation between objective and subjective measures of performance indicators such as ROA and sales growth. They suggest that "where accurate objective measures of performance are available, their use is strongly supported and encouraged, however, if the accurate objective measures are unavailable, then subjective perceptual measures especially, from top management teams, can be considered" (p. 270).

In Turkey, only the firms that were quoted to Istanbul Stock Exchange (BIST-100) have the responsibility of disclosing their financial information to public, periodically. But, since the sample of this study was composed of the privately owned firms and most of the firms did not have the liability and willingness to reveal their financial figures, unavailability of objective performance measures created a necessity for the researcher to use the subjective perceptual measures in the study.

3.3.5 Control variables. Firm age and size were controlled. Given that the specific nature of this study focusses on a wide range of industries, to remove whatever affect it might have on firm performance, industry effects were also systematically controlled by choosing Porter's (1980) five forces industry structure factors. Whilst a couple of demographics questions were used to control age and size effects, industry effects were controlled by the items that were derived and adapted from the Porter's (1980) five forces framework.

3.3.6 Scale. A standard Likert-type scale was used to measure various resource and performance constructs.

\subsection{Reliability and validity tests}

Cronbach's $\alpha$ coefficients were calculated to test the reliability of the constructs. The constructs that had $\alpha$ values equal to and above 0.70 were accepted as reliable 
constructs (Hair et al., 2009). In order to meet the minimum coefficient threshold and gain highest possible reliability, two items were dropped. Whilst "the legally-protected designs" item was eliminated from the IRs construct, "the fixed cost structure required to compete" was dropped from the control variable construct. Table V shows each construct and its Cronbach's $\alpha$ value.

Factor analysis, as a common method, was used to examine construct validity. Factor analysis yielding five factors revealed that all items exceeded the cut-off point 0.50 (Hair et al., 2009). Whilst the whole scale indicated a Cronbach's $\alpha$ reliability value of 0.839 , Cronbach's $\alpha$ values of the constructs' scales were also fairly high: dependent variable - firm performance (0.862), TRs (0.813), capabilities (0.804), IRs (0.749), and control variable - industry structure factors (0.738). The result of the factor analysis is depicted in Table VI.

3.4.1 Correlations between key measures. Highly correlated independent variables can predict each other and may cause problems with multicollinearity which influence the accuracy of the regression analysis negatively (Hair et al., 2009). Although some significant inter-correlations between the independent variables were observed (Table VII), none of the correlation coefficient was above the level considered to be serious, which is generally accepted as 0.80 or higher (Hair et al., 2009). Accordingly, moderate levels of correlations among the independent variables do not seem to create multicollinearity problem.

\subsection{The methodology}

The data were analysed by the computer software "Statistical Package for the Social Science" (IBM - SPSS ${ }^{\circledR}$ ) version 22.0. Apart from the results of the correlation matrix, variance inflation factor (VIF) scores were also calculated for checking the multicollinearity problem. The VIF scores were below the score recommended as problematic, which is 5 (Hair et al., 2013). Furthermore, the results of Kolmogorov-Smirnov test proved that the data were normally distributed. In order to test the established hypotheses, hierarchical regression analysis was used. In hierarchical regression method, each set of independent variables is entered into separate blocks for analysis and the incremental changes of the $R^{2}$ statistics are calculated. Hence, the explanatory power or in other words, the unique contribution of each independent variable in explaining dependent variable is explored (Hair et al., 2013).

\section{Results}

The control variables, industry structure factors and firm-level variables (TR and IR, and capabilities) were entered into regression analysis, respectively, and the contribution of each independent variable was calculated. The abbreviations of the variables are given below:

- $\mathrm{AGE}$ is the firm age;

- SIZE the firm size;

- IND the industry structure factors;

\begin{tabular}{lcccc}
\hline Construct & Initial items & Final items & Cronbach's $\alpha$ & \\
Tangible resources & 7 & 7 & 0.813 & \\
Intangible resources & 13 & 12 & 0.749 & \\
Capabilities & 7 & 7 & 0.804 & Table V. \\
Industry control variable & 12 & 11 & 0.738 & Reliability coefficients \\
Firm performance (dependent variable) & 3 & 3 & 0.862 & \\
\hline
\end{tabular}


EJMBE 26,2

264
Items

Q4. Physical equipment and other physical assets...

Q11. Cash (on hand/at bank) earned from...

Q9. Raised financial capital..

Q16. Buildings and other physical structures...

Q13. Raw material (in stock)...

Q23. Financial investments...

Q21. Land, including its location...

Q7. Legally protected trademarks...

Q1. Contracts and partnerships...

Q14. Brand name reputation..

Q18. Company reputation...

Q3. The operating and reporting structure...

Q8. The shared values, beliefs, attitudes and...

Q26. Product/service reputation...

Q10. Customer service reputation...

Q20. Legally protected patents...

Q12. Employee recruitment, compensation...

Q2. Proprietary/held-in-secret technology...

Q24. Legally protected copyrights...

Q19. Knowledge management and sharing skills...

Q15. The overall skills, creativity, innovativeness...

Q6. The skills, expertise and decision making...

Q25. ERP, supply chain, and logistics systems...

Q17. Relationships that employees and managers...

Q27. Operational processes that support...

Q22. Organisational routines...

Q29. Overall market growth in our industry...

Q35. The degree to which competitors offer...

Q30. The number of competitors vying for...

Q34. The extent to which price competition is used...

Q37. Industry threatened by substitute products...

Q32. The intensity with which competitors jockey...

Q28. Competitors are roughly equal in size and...

Q33. Only a few competitors dominate the market...

Q38. What level of bargaining power on suppliers...

Q36. How easy is it for new firms to enter and...

Q39. What level of bargaining power on customers

Q41. Market share...

Q42. Profitability...

Q40. Sales turnover growth...
F1: TR F2: IR F3: CAP F4: Ind. CONT F5: PER
0.787

0.754

0.739

0.715

0.686

0.613

0.598

0.802

0.792

0.755

0.734

0.721

0.714

0.706

0.699

0.683

0.659

0.639

0.632
0.816
0.785
0.749
0.676
0.623
0.592
0.583

0.838

0.798

0.763

0.737

0.726

0.719

0.693

0.663

0.645

0.614

0.608

Table VI.

Notes: Overall reliability of the scale ( $\alpha=0.839$ ). Factor's Cronbach's $\alpha$ reliability coefficient $\alpha=0.813,0.749$, $0.804,0.738,0.862$. Kaiser-Meyer-Olkin sampling adequacy: $0.9476^{* *}$. Barttlet's test of approx. $\chi^{2}$ sphercity:

$16,435.0 * * * * * 00.01$

- TR the tangible resources;

- IR the intangible resources; and

- CAP the capabilities.

\section{$4.1 \mathrm{H1}$}

Model 1 shows the separate effects of control variables (age, size and industry factors) along with the TRs and their explanatory power in firm performance (see Table VIII). Namely, without other variables, age, size, industry factors and TR explained 12.6 per cent 


\begin{tabular}{|c|c|c|c|c|c|c|c|c|c|c|c|c|}
\hline Variables & Mean & SD & 1 & 2 & 3 & 4 & 5 & 6 & 7 & 8 & 9 & TR and IR \\
\hline \multicolumn{13}{|l|}{ Control } \\
\hline Firm size & 431.63 & 543.26 & 1.00 & & & & & & & & & \\
\hline $\begin{array}{l}\text { Firm age } \\
\text { Industry }\end{array}$ & 34.57 & 31.25 & 0.002 & 1.00 & & & & & & & & \\
\hline factors & 3.267 & 1.236 & -0.007 & -0.112 & 1.00 & & & & & & & 265 \\
\hline \multicolumn{13}{|l|}{ Independent } \\
\hline $\begin{array}{l}\text { Tangible } \\
\text { resources }\end{array}$ & 1.497 & 0.9476 & $0.176^{*}$ & $0.182 *$ & $-0.097 * *$ & 1.00 & & & & & & \\
\hline $\begin{array}{l}\text { Intangible } \\
\text { resources }\end{array}$ & 2.778 & 0.7883 & $0.089 *$ & 0.073 & -0.046 & $0.214 * *$ & 1.00 & & & & & \\
\hline Capabilities & 3.582 & 0.5364 & $0.210^{*}$ & $0.147^{*}$ & 0.003 & $0.186^{* *}$ & $0.265^{* *}$ & 1.00 & & & & \\
\hline \multicolumn{13}{|l|}{ Dependent } \\
\hline $\begin{array}{l}\text { Sales } \\
\text { turnover } \\
\text { Market }\end{array}$ & 5.167 & 1.569 & 0.069 & 0.002 & 0.054 & 0.003 & $0.099 * *$ & $0.281^{* *}$ & 1.00 & & & \\
\hline share & 4.872 & 1.395 & 0.008 & 0.056 & $-0.083 * *$ & $0.110^{* *}$ & $0.164^{* *}$ & $0.376^{* *}$ & $0.393^{* *}$ & 1.00 & & \\
\hline Profitability & 5.329 & 1.482 & $0.095^{* *}$ & $0.143^{*}$ & 0.032 & $0.197^{*}$ & $0.239 * *$ & $0.388^{* *}$ & $0.402 * *$ & $0.436^{* *}$ & 1.00 & Table VII. \\
\hline \multicolumn{12}{|c|}{ Notes: $* p<0.05 ; * * p<0.01$} & tion onlycic \\
\hline
\end{tabular}

$\left(\left(R^{2}=126\right) ;(F=2.345, p<0.05)\right)$ of sales turnover, 8.9 per cent $\left(\left(R^{2}=0.089\right) ;(F=1.438\right.$, $p<0.01))$ of market share and 13.9 per cent $\left(\left(R^{2}=0.139\right) ; \quad(F=2.998, p<0.001)\right)$ of profitability.

Having entered the IRs variable to model 2 , the variations in sales turnover, market share and profitability increased to 15.7 per cent $\left(\left(R^{2}=0.157\right) ;(F=2.761, p<0.05)\right), 10.4$ per cent $\left(\left(R^{2}=0.104\right) ;(F=1.663, p<0.05)\right)$ and 18.1 per cent $\left(\left(R^{2}=0.181\right) ;(F=3.586, p<0.01)\right)$, respectively. Thus, entrance of the IR variable provided an additional and significant explanation power 3.1 per cent $\left(\Delta R^{2}=0.031\right)$ for sales turnover, 1.5 per cent $\left(\Delta R^{2}=0.015\right)$ for market share and 4.2 per cent $\left(\Delta R^{2}=0.042\right)$ for profitability in model 2.

IRs make a unique, individual contribution to firm performance after accounting for the effects of TRs and the control variables (see Table VIII). Across all three performance measures, the IR $\beta$ coefficients are the largest and significant compared to the TR $\beta$ coefficients.

Sales turnover; TR $(\beta=0.194, t=2.745, p<0.001)$; IR $(\beta=0.236, t=2.988, p<0.001)$.

Market share; TR $(\beta=0.078, t=1.367, p<0.01)$; IR $(\beta=0.122, t=2.174, p<0.01)$.

Profitability; TR ( $\beta=0.379, t=3.055, p<0.001)$; IR $(\beta=0.475, t=3.269, p<0.001)$.

Given the analysis results, IRs are positively associated with all performance measures and make a larger contribution to firm performance than TR. Thus, $H 1$ is supported.

\section{$4.2 \mathrm{H} 2$}

Having entered the capabilities variable (CAP) to model 2, significant changes in $R^{2}$ s were observed across all dependent variables (see Table VIII). The variations in sales turnover, market share and profitability increased to 14.9 per cent $\left(\left(R^{2}=0.149\right) ;(F=2.598, p<0.05)\right)$, 11.8 per cent $\left(\left(R^{2}=0.118\right) ;(F=1.742, p<0.01)\right)$ and 21.4 per cent $\left(\left(R^{2}=0.214\right) ;(F=4.136\right.$, $p<0.01)$ ), respectively. Entrance of the CAP variable provided an additional and significant explanation power 2.3 per cent $\left(\Delta R^{2}=0.023\right)$ for sales turnover, 2.9 per cent $\left(\Delta R^{2}=0.029\right)$ for market share and 7.5 per cent $\left(\Delta R^{2}=0.075\right)$ for profitability in model 2 . Therefore, CAP account for significant additional exploratory power to the prediction of the dependent variables after simultaneously accounting for the effects of TR and the control variables. 
EJMBE

26,2

\begin{tabular}{|c|c|c|c|c|c|c|}
\hline \multirow[b]{2}{*}{ Variables } & \multicolumn{2}{|c|}{ Sales turnover } & \multicolumn{2}{|c|}{ Market share } & \multicolumn{2}{|c|}{ Profitability } \\
\hline & $\beta$ & $t$ & $\beta$ & $t$ & $\beta$ & $t$ \\
\hline \multicolumn{7}{|l|}{ H1 } \\
\hline Constant & - & $6.548^{* * * *}$ & - & $6.933 * * *$ & - & $7.425^{* *}$ \\
\hline AGE & 0.023 & 0.398 & -0.044 & -0.359 & -0.127 & -0.446 \\
\hline SIZE & 0.019 & 0.736 & 0.009 & 0.547 & 0.016 & 0.697 \\
\hline IND & 0.073 & $1.263^{* *}$ & 0.139 & $1.941 * *$ & -0.008 & -1.897 \\
\hline TR & 0.194 & $2.745 * * *$ & 0.078 & $1.367 * *$ & 0.379 & $3.055^{* * * *}$ \\
\hline IR & 0.236 & $2.988^{* * * *}$ & 0.122 & $2.174^{* *}$ & 0.475 & $3.269^{* * * *}$ \\
\hline \multicolumn{7}{|l|}{ Model 1 (w/out IR) } \\
\hline$R^{2}$ & \multirow{2}{*}{\multicolumn{2}{|c|}{0.126}} & \multicolumn{2}{|c|}{0.089} & \multicolumn{2}{|c|}{0.139} \\
\hline$F$ & & & \multicolumn{2}{|c|}{$1.438 * *$} & \multicolumn{2}{|r|}{$2.998 * * *$} \\
\hline \multicolumn{5}{|l|}{ Model 2 (with IR) } & & \\
\hline$R^{2}$ & \multicolumn{2}{|c|}{0.157} & \multicolumn{2}{|c|}{0.104} & \multirow{2}{*}{\multicolumn{2}{|c|}{0.181}} \\
\hline$\Delta R^{2}$ (change in $R^{2}$ ) & \multicolumn{2}{|c|}{0.031} & \multicolumn{2}{|c|}{0.015} & & \\
\hline$F$ & \multicolumn{2}{|c|}{$2.761 *$} & \multicolumn{2}{|c|}{$1.663^{*}$} & \multicolumn{2}{|c|}{$3.586 * *$} \\
\hline
\end{tabular}

H2

Constant

AGE

SIZE

IND

TR

CAP

Model 1 (w/out CAP)

$R^{2}$

Model 2 (with CAP)

$R^{2} \quad 0.149$

$\frac{\Delta R^{2}}{F}$ (change in $R^{2}$ )

$\begin{array}{ll}- & 6.239^{* * *} \\ 0.019 & 0.364 \\ 0.004 & 0.547 \\ 0.056 & 1.092^{* *} \\ 0.178 & 2.431^{* *} \\ 0.304 & 3.247^{* *}\end{array}$

-
-0.062
0.052
0.116
0.063
0.156

$6.128^{* * * *}$
-0.386
0.603
$1.897^{*}$
$1.184^{* *}$
$2.105^{* *}$

-
-0.045
0.013
-0.014
0.204
0.498

$7298 * *$

0.126

$2.345^{*}$

0.089

$1.438^{* *}$

$-0.239$

0.655

$-1.933$

$2.446^{* * *}$

0.023

0.118

0.029

$1.742^{* * *}$

$3.507^{* *}$

H3

$2.598^{*}$

Constant

AGE

SIZE

IND

IR

CAP

Model 1 (w/out CAP)

$R^{2}$

Model 2 (with CAP)

$R^{2}$
$\Delta R^{2}$ (change in $\left.R^{2}\right)$

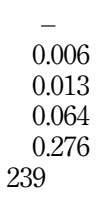

H4

Constant

AGE

SIZE

IND

TR

IR

CAP
0.006

0.013

0.064

239

$$
\begin{aligned}
& 6.933^{* * *} \\
& 0.286 \\
& 0.654 \\
& 1.213^{* * *} \\
& 3.134^{*} \\
& 3.002^{*}
\end{aligned}
$$

0.151

$2.767^{* * * *}$

0.165

0.014

$2.087^{* *}$
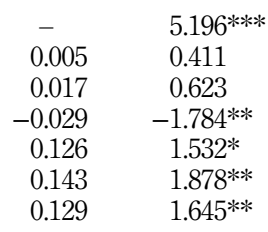

0.002

0.052

0.103

0.147

0.135

0.103

$1.665^{* *}$

0.124

0.021

$1.865 * *$

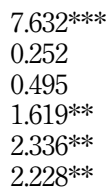

$2.228 * *$

Table VIII.

Statistics of hypotheses
- $4.875^{* * * *}$

$-0.006$

0.003

$-0.054$

0.056

0.152

0.121

$$
\begin{gathered}
4.875^{* * * *} \\
-0.312 \\
0.431 \\
-1.863^{* *} \\
1.418^{* *} \\
1.965^{* *} \\
1.629^{* *}
\end{gathered}
$$

$-\overline{0} 003$

$-0.013$

0.028

0.287

0.363

0.176

3.459 ****

0.203

0.027

$3.631^{* * * *}$

$$
\begin{array}{r}
- \\
-0.004 \\
0.008 \\
-0.011 \\
0.109 \\
0.262 \\
0.311
\end{array}
$$

\section{6}

0.139

$2.998 * * *$

0.214

0.075

$4.136^{* *}$

$$
\begin{aligned}
& 8.038^{* * * *} \\
& 0.206 \\
& -0.449 \\
& 1.553 \\
& 2.165^{* *} \\
& 3.198^{* *}
\end{aligned}
$$

$$
\begin{aligned}
& 5.683^{* * *} \\
& -0.373 \\
& 0.505 \\
& -1.442 \\
& 1.769^{*} \\
& 2.477^{* *} \\
& 2.881^{* *}
\end{aligned}
$$




\begin{tabular}{|c|c|c|c|c|}
\hline \multirow[b]{2}{*}{ Variables } & Sales turnover & Market share & Profitability & Contribution \\
\hline & $\beta$ & $\beta$ & $\beta$ & \\
\hline \multicolumn{5}{|l|}{ Model 1 (w/out CAP) } \\
\hline$R^{2}$ & 0.157 & 0.104 & 0.181 & \\
\hline$F$ & $2.761^{*}$ & $1.663^{*}$ & $3.586^{* * *}$ & \\
\hline \multicolumn{5}{|l|}{ Model 2 (with CAP) } \\
\hline$\Delta R^{2}$ (change in $R^{2}$ ) & $\begin{array}{l}0.166 \\
0.009\end{array}$ & $\begin{array}{l}0.116 \\
0.012\end{array}$ & $\begin{array}{l}0.209 \\
0.028\end{array}$ & 201 \\
\hline$F$ & 2.330 & $2.017^{* *}$ & $2.884^{* *}$ & \\
\hline \multicolumn{4}{|c|}{ Notes: $* p<0.05 ; * * p<0.01 ; * * * p<0.001$} & Table VIII \\
\hline
\end{tabular}

CAP have the largest $\beta$ coefficients of any of the independent variables in the regression model (see Table VIII). In H2, CAP have a larger $\beta$ coefficient across all of the performance measures, than TR as shown below.

Sales turnover; TR $(\beta=0.178, t=2.431, p<0.01)$; CAP $(\beta=0.304, t=3.247, p<0.01)$.

Market share; TR $(\beta=0.063, t=1.184, p<0.01)$; CAP $(\beta=0.156, t=2.105, p<0.01)$.

Profitability; TR $(\beta=0.204, t=2.446, p<0.01)$; CAP $(\beta=0.498, t=3.507, p<0.01)$.

These results suggest that $\mathrm{CAP}$ are positively associated with all performance measures and more important to explaining firm performance than TR. Therefore, the findings of the analysis offer support for $H 2$.

\section{$4.3 \mathrm{H} 3$}

The addition of CAP to model 2 that includes control variables along with IR results significant changes in $R^{2}$ s across all performance measures (see Table VIII). The variations in sales turnover, market share and profitability increased to 16.5 per cent $\left(\left(R^{2}=0.165\right)\right.$; $(F=2.087, p<0.01))$, 12.4 per cent $\left(\left(R^{2}=0.124\right) ;(F=1.865, p<0.01)\right)$ and 20.3 per cent $\left(\left(R^{2}=0.203\right) ; \quad(F=3.631, p<0.001)\right)$, respectively. Entrance of the CAP provided an additional and significant explanation power 1.4 per cent $\left(\Delta R^{2}=0.014\right)$ for sales turnover, 2.1 per cent $\left(\Delta R^{2}=0.021\right)$ for market share and 2.7 per cent $\left(\Delta R^{2}=0.027\right)$ for profitability in the regression model. Thus, CAP account for significant additional exploratory power to the prediction of the dependent variables after simultaneously accounting for the effects of IR and the control variables.

With regard to the unique, individual contribution of CAP to explain performance relative to the other independent variables, the results were mixed (see Table VIII). For sales turnover, the $\beta$ coefficient for CAP was $\beta=0.239(t=3.002, p<0.05)$ which was smaller than IR coefficient of $\beta=0.276(t=3.134, p<0.05)$. Similarly, for market share, the $\beta$ coefficient for CAP was $\beta=0.135(t=1.184, p<0.01)$ which was also smaller than IR coefficient of $\beta=0.147$ $(t=2.336, p<0.01)$. For profitability, the $\beta$ coefficient for CAP was $\beta=0.363(t=3.198$, $p<0.01)$ compared to IR coefficient of $\beta=0.287(t=2.165, p<0.01)$. Given these results, CAP make larger contributions in only one of the three dependent variables that is profitability. Thus, the findings of the analysis offer only partial support for $H 3$.

\section{$4.4 \mathrm{H} 4$}

The addition of CAP to the model including the control variables along with the combined contributions of TR and IR results significant $R^{2}$ change only for profitability (see Table VIII). Whilst entrance of the CAP increased explanation power of the model significantly from $R^{2}=0.181$ to $R^{2}=0.209 \quad\left(\left(\Delta R^{2}=0.028\right) ; \quad(F=02.884, p<0.01)\right)$ for profitability, $R^{2}$ changes in sales turnover and market share were non-significant. Hence, in only profitability do CAP account for significant additional explanatory power to the prediction 
EJMBE

26,2

268

of firm performance after simultaneously accounting for the effects of both TR and IR along with the control variables.

With regard to the unique, individual contribution of CAP to explain performance relative to TR and IR, the results were weak (see Table VIII). For sales turnover, the $\beta$ coefficient for CAP was $\beta=0.129(t=1.645, p<0.01)$ which was smaller than IR coefficient of $\beta=0.143(t=1.878, p<0.01)$ and slightly larger than TR coefficient of $\beta=0.126(t=1.532, p<0.05)$. For market share, the $\beta$ coefficient for CAP was $\beta=0.121$ $(t=1.629, p<0.01)$ which was again smaller than IR coefficient of $\beta=0.152(t=1.965$, $p<0.01)$ but larger than TR coefficient of $\beta=0.056(t=1.418, p<0.01)$. For only profitability, the $\beta$ coefficient for CAP was $\beta=0.311(t=2.881, p<0.01)$ larger compared to $\beta=0.109(t=1.769, p<0.05)$ of TR and $\beta=0.262(t=2.477, p<0.01)$ of IR.

Given these results, CAP make larger contributions in only one of the three dependent variables that is profitability. Thus, the findings of the analysis do not offer support for $\mathrm{H}$.

Based on the results of the statistical analysis, only two hypotheses that posited the larger contributions of IRs $(H 1)$ and capabilities $(H 2)$ on firm performance compared to TRs were fully accepted. Whilst the data that were analysed offered only a partial support for $H 3$ that posited a larger contribution of capabilities on firm performance compared to IRs, $H 4$ suggesting a larger contribution of capabilities compared to the combined contribution of TR and IR was rejected. A summary of the findings was presented in Table IX.

\section{Discussion and managerial implications}

The analysis revealed some noteworthy results. In testing the $H 1$, although the relative contribution of IRs was significantly higher than TRs, the difference was not considerable and TRs were still significantly associated with all performance measures (especially with sales turnover) and offered unique contributions to firm performance. Moreover, the additional explanatory power of IRs on performance measures was significant but limited. These results show that against the dominant effect of IRs on performance, TRs still have a non-negligible impact in contributing firm performance within the context of Turkish business environment.

\subsection{Unexpected TR effects}

The reason for this unexpected TR effect on performance may be linked to the previous competitive strategy choices of the Turkish firms in global markets. With the support of low labour cost, most of the Turkish firms preferred adopting a low-cost strategy and investing on TRs that enable the firms achieve high amount of production. A low-cost strategy relies "heavily on the ability to improve the manufacturing efficiencies in the firm's value chain" (Spanos et al., 2001, p. 643). Although manufacturing efficiency can be increased through IRs such as just-in-time and LEAN manufacturing software, relative effects of the TRs such as low-cost raw material and labour, modern machinery and equipment, and physical

H1: intangible resources will make a larger contribution to firm performance than that of Supported tangible resources

H2: capabilities will make a larger contribution to firm performance than that of tangible Supported resources

H3: capabilities will make a larger contribution to firm performance than that of Partially supported

Table IX.

Summary of results intangible resources

H4: capabilities will make a larger contribution to firm performance than the combined Not supported contributions of tangible and intangible resources 
buildings and manufacturing plants are greater (Grimpe and Hussinger, 2014). Another factor that can explain the finding of strong TR effect on firm performance is that until early 2000s, the Turkish trade and commercial laws did not have deterrent penalties against the firms violating intellectual property rights in the country. Hence, this situation might also direct Turkish firms to focus on just manufacturing at lower costs in order to sustain competitive advantage rather than offering differentiated services and products to the markets. Under these conditions, many Turkish firms developed a special expertise for manufacturing imitated products (e.g. Lacoste, Louis Vuitton and Tommy Hilfiger). Developed countries have a strong historical economic tradition based on free market structure, liberalisation and legal protection for intellectual property which enabled the firms of these countries make relatively more thorough strategic decisions in line with the requirements of new economy where service sector has a high share and IRs are in the focal concern. So, the discrepancies concerning the relative importance of TR vs IR and capabilities on firm performance between the results of similar types of studies conducted in Western countries (Spanos and Lioukas, 2001; Galbreath and Galvin, 2006; Weigelt, 2013) can be explained in this manner and this study may be attributed to the remnants of the past Turkish economic growth model and competitive strategy choices of the Turkish firms.

In $H 2$, the capabilities did not only contribute firm performance significantly higher than TRs, but they also accounted for the largest $\beta$ values in the context of all hypotheses and regression models. Moreover, apart from the profitability measure on which a considerable contribution was achieved, capabilities provided significant but relatively limited contribution to other performance measures. Therefore, evidence was found to suggest that capabilities are among the most important determinants of a firm's market and particularly, financial performance.

A partial support was offered for $H 3$ which examined the relative impact of capabilities compared to IRs. One explanation for this partial support might rest with capability and IR interconnectedness (Dierickx and Cool, 1989; Sirmon et al., 2011). For example, reputational resources (e.g. corporate reputation, customer/product service reputation or brand name) which are among the IR categories might be described as an outcome or the result of previous successful marketing or communication activities of a firm's managerial and/or networking capabilities. In another example, IT systems or collaborative platforms which are among the capability constructs might be described as the outcomes of the in-house developed software that is an IR construct. Hence, when taken in the context of the broader resources necessary to build a capability such as an IT system, its impact on firm performance measures might not be as significant as found by past studies, many of which isolate on an IT system as a stand-alone capability (Ray et al., 2004, 2013). Lastly, the findings demonstrate that idiosyncratic stock of static resources and capabilities that are dynamic in nature become complementary while they create performance and they are likely to represent "the two sides of the same coin" (Wernerfelt, 1984).

The findings of the final $\mathrm{H} 4$ were inconclusive. Capabilities offered rather limited additional explanatory power to the prediction of firm performance only with respect to profitability against the combined effects of TR and IR. One possible explanation for the rejection of $(H 4)$ is that the hypotheses of this study were too broadly stated and firm performance was measured too narrowly. In reality, different resource categories and different types of capabilities may have varying influence on firm performance. As an example, the effects of human capital (which is a DC) may vary across different manifestations of firm performance but human capital which consists a number of human-related skills such as leadership and strategic decision-making abilities, employee know-how, creative skills of managers and/or employees, etc. was considered as a general capability construct. However, each skill that constitutes a whole capability construct can have different indirect effects within the context of different performance constructs such as 
EJMBE 26,2

number of new products and processes developed, new ideas generated, strategic partnerships established that may be the predictors of market and financial performance constructs used in this study. Although these skills, to some extent, may create performance repercussions on the final performance constructs, their real performance effects might largely remain on the mediating performance constructs.

\subsection{Capabilities as determinants of performance}

As an ultimate point, capabilities were found as the most important determinants of firm performance in the Turkish business context. Our capability construct included three sub-categories: human capital, networking capabilities and business processes. Although those sub-category capabilities have generated a total impact on firm performance as a general capability construct, their influence should be analysed separately.

Human capital can be seen as an important strategic initiative and enabler in the process of performance creation in the Turkish business context. One explanation for the important role of human capital might be related to the lack of high quality human resource and the existence of inefficiency in working life in the country (World Economic Forum, 2013). Given the conditions of incapability and inefficiency among workforce, more managerial supervision, initiation, control and interaction is required. Furthermore, integration of highly dynamic business environment with incapable workforce may complicate jobs of the managers and compel them to be even more interactive and intervening in every business function of the firms. Bearing in mind that, continuing immigration of skilled human capital from Turkey to Western countries (World Economic Forum, 2013) may have worsened the situation and due to the lack of necessary skilled human resource stock in the country, the qualified managers in firms may have taken additional burdens on their shoulders that force them to be more intervener and interactive in the process of firm performance creation. This position may increase the need of highly skilled employees even more and hence, the participants may have emphasised the vital importance of human capital for performance in the research. Thus, acquiring, attracting, retaining and motivating human capital through effective HRM policies such as developing a unique culture via shaping the spoken and unspoken norms and rules of the firm that creates a working atmosphere and environment for maximum worker productivity and performance should be management priorities.

With respect to networking capabilities, Turkey is a country where nepotism, friendship and trust-based relationship can be seen in every part of life as well as business life (Ozbilgin, 2011). Moreover, existence of poor institutional environment which leads to corruption, high levels of bureaucracy and red tape that can result to inefficiencies may compel firms to establish relations with politicians and bureaucrats. Therefore, given these characteristics of the country, the firms in Turkey may have developed special networking capabilities for relationship-based management. As a managerial implication, managers of the firms in Turkey should spend much of their time on day-to-day operations and establish relations with executives in governmental institutions. The development plans and programmes of political parties should be followed by managers cautiously. As such, the recent administrations which attempt to execute some economic activities with religious references (e.g. 0 per cent interest in the economy, extreme limitation for the sales of alcoholic beverages, utilisation of public services for some groups tendentiously) should be considered for the efficacy of managerial planning and control.

Relating to business processes, rapid and discontinuous changes are common in Turkish economy where political instability, financial volatility and discursive consumer shifts occur. In this situation, business processes such as IT skills, ERP, EDI and SCM systems enable firms to have sufficient intelligence pertaining to current and future customer needs, competitor strategies and actions, channel requirements, and the broader business environment and provide them agility to respond market demands quickly (Ray et al., 2004, 2013). 
Since the firms in Turkey operated in a harsh business environment, most of them survived by finding idiosyncratic solutions to the unpredicted and unexpected problems, adopting new alternative strategies, or modifying the existing ones that increase the speed and scope of their strategic manoeuvring actions. Hence, Turkish firms may have given priority to invest in business processes to address their strategic flexibility requirements and after a while they may have acquired special skills to be able to operate in unreliable business environments. Given the hyper changing business conditions in the country, managers of the firms should pay attention to establish early warning systems along with rapid information and market intelligence providing mechanisms. In this sense, allocation of resources in favour of business process development such as strengthening IT infrastructure, SCM and logistics systems should be a concern for managers. However, resource allocation and the optimal deployment of strategic resources is a key managerial challenge and priority should be given to the most important ones.

\section{Limitations and future research directions}

Three limitations are highlighted in this study: first, the context-specific nature of firm-level resources compelled the researcher to establish the hypotheses testing the relative importance of resources on firm performance empirically in broad nature. Namely, only general resource categories, TR and IR, and capabilities were used but sub-categories of these resources were omitted. As a future research direction, a construct set that includes a broader but not exhaustive number of resources and capabilities might be helpful for a better investigation of resource and capability and performance relationship.

Second, in all research, objective performance measures should be used where possible and available. However, given the limitation of obtaining the financial figures of the firms investigated that were not offered to public, this research uses perception-based performance measurement. Thus, it should be noted that performance evaluations of top level managers might produce biased results.

Third, the cross-sectional nature of the study provides a snapshot about the issue for a specific point in time but gives no indication of the sequence of events. Therefore, the findings of this study are not guaranteed to be representative for the following years and need validation and verification over time.

Fourth, limitation of this research is about what is captured and not captured with respect to resource and capability effects. Some resources and/or capabilities may predict each other and affect their power of impact on performance. So, whether some resources or capabilities might be contributing to competitive advantage in some unique way as a mere reflection of a resource (or a capability) that is necessary to maintain survival in the market, or are an effect resulted from the resource-capability interaction is not known. Although research findings provide valuable insights with respect to resource and capability contribution to firm performance, the mechanisms (moderating and mediating effects) between resource and capability interactions in performance creation are more than just complex and need further investigation and also some degree of confirmation.

\section{References}

Acquaah, M. (2012), "Social networking relationships, firm-specific managerial experience and firm performance in a transition economy: a comparative analysis of family owned and nonfamily firms”, Strategic Management Journal, Vol. 33 No. 10, pp. 1215-1228.

Ambrosini, V. and Bowman, C. (2009), "What are dynamic capabilities and are they a useful construct in strategic management?", International Journal of Management Reviews, Vol. 11 No. 1, pp. 29-49. 
EJMBE 26,2

Arend, J.R., Patel, P. and Park, H.D. (2014), "Explaining post-IPO venture performance through a knowledge-based view typology", Strategic Management Journal, Vol. 35 No. 3, pp. 376-397.

Barney, J.B. (1991), "Firm resources and sustained competitive advantage", Journal of Management, Vol. 17 No. 1, pp. 99-120.

Barney, J.B. (2012), "Purchasing, supply chain management and sustained competitive advantage: the relevance of resource-based theory", Journal of Supply Chain Management, Vol. 48 No. 2, pp. 3-6.

Bauer, F. and Matzler, K. (2014), "Antecedents of M\&A success: the role of strategic complementarity, cultural fit, and degree and speed of integration", Strategic Management Journal, Vol. 35 No. 2, pp. 269-291.

Bharadwaj, A.S. (2000), "A resource-based perspective on information technology capability and firm performance: an empirical investigation”, MIS Quarterly, Vol. 24 No. 1, pp. 169-196.

Carmeli, A. and Tishler, A. (2004), "The relationships between intangible organizational elements and organizational performance”, Strategic Management Journal, Vol. 25 No. 13, pp. 1257-1278.

Cavusgil, T., Ghauri, P.N. and Akcal, A.A. (2013), Doing Business in Emerging Markets, 2nd ed., Sage Publications, London.

Chari, M.D.R. and David, P. (2012), "Sustaining superior performance in an emerging economy: an empirical test in the Indian context”, Strategic Management Journal, Vol. 33 No. 2, pp. 217-229.

Chatterji, A. and Patro, A. (2014), "Dynamic capabilities and managing human capital", Academy of Management Perspectives, Vol. 28 No. 4, pp. 395-408.

Coff, R. and Kryscynski, D. (2011), "Drilling for micro-foundations of human capital-based competitive advantages", Journal of Management, Vol. 37 No. 5, pp. 1429-1443.

Dess, G.G. and Robinson, R.B. (1984), "Measuring organizational performance in the absence of objective measures: the case of the privately-held firm and conglomerate business unit", Strategic Management Journal, Vol. 5 No. 3, pp. 265-273.

Di Stefano, G., Peteraf, M. and Verona, G. (2014), "The organizational drivetrain: a road to integration of dynamic capabilities research", Academy of Management Perspectives, Vol. 28 No. 4, pp. 307-327.

Dierickx, I. and Cool, K. (1989), "Asset stock accumulation and sustainability of competitive advantage”, Management Science, Vol. 35 No. 12, pp. 1504-1511.

Dowling, G.R. (2016), "Defining and measuring corporate reputations”, European Management Review, Vol. 13 No. 3, pp. 207-223.

Eesley, C.E., Hsu, D.H. and Roberts, E.B. (2014), "The contingent effects of top management teams on venture performance: aligning founding team composition with innovation strategy and commercialization environment", Strategic Management Journal, Vol. 35 No. 12, pp. 1798-1817.

Fahy, J. (2002), "A resource-based analysis of sustainable competitive advantage in a global environment”, International Business Review, Vol. 11 No. 1, pp. 57-78.

Fainshmidt, S., Pezeshkan, A., Frazier, M.L., Nair, A. and Markowski, E. (2016), "Dynamic capabilities and organizational performance: a meta-analytic evaluation and extension", Journal of Management Studies, Vol. 53 No. 8, pp. 1348-1379.

Fonti, F., Maoret, M. and Whitbred, R. (2017), "Free-riding in multi-party alliances: the role of perceived alliance effectiveness and peers' collaboration in a research consortium”, Strategic Management Journal, Vol. 38 No. 2, pp. 363-383.

Galbreath, J. (2004), "Determinants of firm success: a resource-based analysis”, unpublished doctoral dissertation, Curtin University of Technology.

Galbreath, J. and Galvin, P. (2006), "Accounting for performance variation: how important are intangible resources?", International Journal of Organizational Analysis, Vol. 14 No. 2, pp. 150-170.

Galbreath, J. and Galvin, P. (2008), "Firm factors, industry structure and performance variation: new empirical evidence to a classic debate", Journal of Business Research, Vol. 61 No. 2, pp. 109-117. 
Grimpe, C. and Hussinger, K. (2014), "Resource complementarity and value capture in firm acquisitions: the role of intellectual property rights", Strategic Management Journal, Vol. 35 No. 12, pp. 1762-1780.

Gupta, A., Briscoe, F. and Hambrick, D.C. (2017), "Red, blue, and purple firms: organizational political ideology and corporate social responsibility", Strategic Management Journal, Vol. 38 No. 5, pp. 1018-1040.

Hair, J.F., Black, W.C., Babin, B.J. and Anderson, R.E. (2009), Multivariate Data Analysis, 7th ed., Prentice Hall, Englewood Cliff, NJ.

Hair, J.F., Hult, G.T.M., Ringle, C.M. and Sarstedt, M. (2013), A Primer on Partial Least Squares Structural Equation Modeling (PLS-SEM), Sage, Thousand Oaks, CA.

Hall, R. (1992), "The strategic analysis of intangible resources", Strategic Management Journal, Vol. 13 No. 2, pp. 135-144.

Helfat, C.E. and Martin, J.A. (2015), "Dynamic managerial capabilities: review and assessment of managerial impact on strategic change", Journal of Management, Vol. 41 No. 5, pp. 1281-1312.

Helfat, C.E. and Peteraf, M.A. (2015), "Managerial cognitive capabilities and the micro-foundations of dynamic capabilities", Strategic Management Journal, Vol. 36 No. 6, pp. 831-850.

Hult, G.T.M., Ketchen, D.J. and Arrfelt, M. (2007), "Strategic supply chain management: improving performance through a culture of competitiveness and knowledge development", Strategic Management Journal, Vol. 28 No. 10, pp. 1035-1052.

Huselid, M. (1995), "The impact of human resource management practices on turnover, productivity, and corporate financial performance", Academy of Management Journal, Vol. 38 No. 3, pp. 635-672.

IMF World Economic Outlook (2017), "World economic outlook”, available at: www.imf.org/external/ country/TUR/index.htm (accessed 9 March 2017).

ISO-1000 Database (2016), "The first largest 500 firms and the second largest 500 industrial firms of Turkey”, available at: www.iso.org.tr/projeler/turkiyenin-500-buyuk-sanayi-kurulusu/ (accessed 21 February 2016).

Kamal, S. (2011), "Entry mode and subsidiary performance in emerging economies", Mustang Journal of Business and Ethics, Vol. 2 No. 1, pp. 20-29.

Kor, Y. and Mesko, A. (2013), "Dynamic managerial capabilities: configuration and orchestration of top executives' capabilities and the firm's dominant logic", Strategic Management Journal, Vol. 34 No. 2, pp. 233-244.

Lockett, A., Thompson, S. and Morgenstern, U. (2009), "The development of the resource-based view of the firm: a critical appraisal", International Journal of Management Reviews, Vol. 11 No. 1, pp. 9-28.

McGahan, A.M. and Porter, M. (1997), "How much does industry matter, really?", Strategic Management Journal, Vol. 18 No. 1, pp. 5-14.

Makhija, M. (2003), "Comparing the resource-based and market-based views of the firm: empirical evidence from Czech privatization”, Strategic Management Journal, Vol. 24 No. 5, pp. 433-451.

Maritan, A.C. and Peteraf, M.A. (2011), "Building a bridge between resource acquisition and resource accumulation”, Journal of Management, Vol. 37 No. 5, pp. 1374-1389.

Molina-Azorin, J.F. (2012), "Mixed-methods research in strategic management: impact and applications", Organizational Research Methods, Vol. 15 No. 1, pp. 33-56.

Molloy, J. and Barney, J. (2015), "Who captures the value created with human capital? A market-based view”, Academy of Management Perspectives, Vol. 29 No. 3, pp. 309-325.

Monteiro, F. and Birkinshaw, J. (2016), "The external knowledge sourcing process in multinational corporations", Strategic Management Journal, Vol. 38 No. 2, pp. 342-362.

Morgan, N.A., Vorhies, D.W. and Mason, C.H. (2009), "Market orientation, marketing capabilities and firm performance”, Strategic Management Journal, Vol. 30 No. 8, pp. 909-920. 
EJMBE 26,2

Morris, S.S., Alvarez, S.A., Barney, J.B. and Molloy, J.C. (2017), "Firm-specific human capital investments as a signal of general value: revisiting assumptions about human capital and how it is managed", Strategic Management Journal, Vol. 38 No. 4, pp. 912-919.

Ozbilgin, M.F. (2011), "Leadership in Turkey: toward an evidence based and contextual approach", in Metcalfe, B. and Mimouni, F. (Eds), Leadership Development in the Middle East, Edward Elgar Publishing, Cheltenham, pp. 275-296.

Ozer, M. and Zhang, W. (2015), "The effects of geographic and network ties on exploitative and exploratory product innovation”, Strategic Management Journal, Vol. 36 No. 7, pp. 1105-1114.

Peteraf, M. and Barney, J.B. (2003), "Unravelling the resource-based tangle", Managerial and Decision Economics, Vol. 24 No. 4, pp. 309-323.

Ployhart, R.E. and Moliterno, T.P. (2011), "Emergence of the human capital resource: a multilevel model", Academy of Management Review, Vol. 36 No. 1, pp. 127-150.

Porter, M.E. (1980), Competitive Strategy, The Free Press, New York, NY.

Porter, M.E. (1991), "Towards a dynamic theory of strategy”, Strategic Management Journal, Vol. 12 No. 1 , pp. 95-117.

Quigley, T.J., Crossland, C. and Campbell, R.J. (2017), "Shareholder perceptions of the changing impact of CEOs: market reactions to unexpected CEO deaths, 1950-2009", Strategic Management Journal, Vol. 38 No. 4, pp. 939-949.

Raithel, S. and Schwaiger, M. (2015), "The effects of corporate reputation perceptions of the general public on shareholder value", Strategic Management Journal, Vol. 36 No. 6, pp. 945-956.

Ray, G., Barney, J.B. and Muhanna, W.A. (2004), "Capabilities, business processes, and competitive advantage: choosing the dependent variable in empirical tests of the resource-based view", Strategic Management Journal, Vol. 25 No. 1, pp. 23-37.

Ray, G., Xue, L. and Barney, J.B. (2013), "Impact of information technology capital on firm scope and performance: the role of asset characteristics", Academy of Management Journal, Vol. 56 No. 4, pp. 1125-1147.

Renzi, A. and Simone, C. (2011), "Innovation, tangible and intangible resources: the space of slacks interaction", Strategic Change, Vol. 20 Nos 1-2, pp. 59-71.

Sánchez, A.A., Marín, G.S. and Morales, A.M. (2015), "The mediating effect of strategic human resource practices on knowledge management and firm performance", European Journal of Management \& Business Economics, Vol. 24 No. 3, pp. 138-148.

Saunders, M., Lewis, P. and Thornhill, A. (2007), Research Methods for Business Students, 4th ed., Pearson Education, Essex.

Schriber, S. (2015), "Tangible resources and the development of organizational capabilities", Scandinavian Journal of Management, Vol. 31 No. 1, pp. 54-68.

Short, J.C., McKelvie, A., Ketchen, D.J. and Chandler, G.N. (2009), "Firm and industry effects on firm performance: a generalization and extension for new ventures", Strategic Entrepreneurship Journal, Vol. 3 No. 1, pp. 47-65.

Sirmon, D.G., Hitt, M.A., Ireland, R.D. and Gilbert, B.A. (2011), "Resource orchestration to create competitive advantage: breadth, depth, and life cycle effects", Journal of Management, Vol. 37 No. 5, pp. 1390-1412.

Spanos, Y.E. and Lioukas, S. (2001), "An examination of the causal logic of rent generation: contrasting Porter's competitive strategy framework and the resource-based perspective", Strategic Management Journal, Vol. 22 No. 10, pp. 907-934.

Spanos, Y., Prastacos, G. and Papadakis, V. (2001), "Greek firms and EMU: contrasting SMEs and large sized enterprises”, European Management Journal, Vol. 19 No. 6, pp. 638-648.

Teece, D.J. (2007), "Explicating dynamic capabilities: the nature and micro-foundations of (sustainable) enterprise performance", Strategic Management Journal, Vol. 28 No. 13, pp. 1319-1350.

Venkatraman, N. and Ramanujam, V. (1986), "Measurement of business performance in strategy research: a comparison of approaches", The Academy of Management Review, Vol. 11 No. 4, pp. 801-814. 
Venkatraman, N. and Ramanujam, V. (1987), "Measurement of business economic performance: an examination of method convergence", Journal of Management, Vol. 13 No. 1, pp. 109-122.

Wang, C.L., Senaratne, C. and Rafiq, M. (2015), "Success traps, dynamic capabilities and firm performance", British Journal of Management, Vol. 26 No. 1, pp. 26-44.

Wei, J., OuYang, Z. and Chen, H.A. (2017), "Well-known or well-liked? The effects of corporate reputation on firm value at the onset of a corporate crisis", Strategic Management Journal, doi: $10.1002 / \mathrm{smj} .2639$.

Weigelt, C. (2013), "Leveraging supplier capabilities: the role of locus of capability deployment", Strategic Management Journal, Vol. 34 No. 1, pp. 1-21.

Wernerfelt, B. (1984), “A resource-based view of the firm”, Strategic Management Journal, Vol. 5 No. 2, pp. 171-180.

World Economic Forum (2013), "Human Capital Index 2013”, available at: http://reports.weforum.org/ human-capital-index-2013/ (accessed 6 November 2014).

Yayavaram, S. and Chen, W.R. (2015), "Changes in firm knowledge couplings and firm innovation performance: the moderating role of technological complexity", Strategic Management Journal, Vol. 36 No. 3, pp. 377-396.

\section{Further reading}

Kamasak, R. (2014), "The contribution of tangible and intangible resources, and capabilities to a firm's profitability and market performance: empirical evidence from Turkey", unpublished $\mathrm{PhD}$ thesis, The University of Exeter, Exeter.

\section{Corresponding author}

Rifat Kamasak can be contacted at: rifat.kamasak@eas.bau.edu.tr

For instructions on how to order reprints of this article, please visit our website: 